\title{
Effect of cytokine growth factors on the prevention of acute wound failure
}

\author{
MARTIN C. ROBSON, MDa; DEREK A. DUBAY, MD ; XUE WANG, MD, PhD ${ }^{b}$; MICHAEL G. FRANZ, MD
}

Cytokine growth factor treatment of chronic wounds has met with mixed results. The chronic wound presents a hostile environment to peptides such as growth factors. Cytokine growth factors have not been studied extensively in acute wounds. However, incisional hernias are a major example of acute wound failure that has not been solved by various mechanical approaches. A biological approach to acute wound failure by use of cytokine growth factors may offer a new strategy. A rodent incisional hernia model was used. Seventysix rats underwent $3-\mathrm{cm}$ midline celiotomies and were closed with fine, fast-absorbing sutures to induce intentional acute wound failure. Group 1 received no other treatment. The midline fascia in Groups 2-10 was infiltrated with $100 \mu \mathrm{l}$ of vehicle alone or vehicle containing various test cytokine growth factors. Necropsy was performed on postoperative day 28 and the wounds were examined for herniation. Incisional hernias developed in 83 percent (13/16) of untreated incisional and 88 percent (7/8) and 83 percent (5/6) of the two vehicle-treated incisions (PBS and carboxymethylcellulose). Hernia incidences were decreased by priming of the fascial incision with transforming growth factor- $\beta_{2}(12 \%, 1 / 8)$, basic fibroblast growth factor $(25 \%, 2 / 8)$ and interleukin-1 $\beta(50 \%, 3 / 6)(p<0.05)$. Aqueous platelet-derived growth factor, becaplermin, insulin-like growth factor, and granulocyte macrophage-colony stimulating factor did not significantly decrease the incidence of acute wound failure $(p>0.05)$. A biological approach to acute wound failure as measured by incisional hernia formation can be useful in reducing the incidence of this complication. Transforming growth factor- $\beta_{2}$, basic fibroblast growth factor, and interleukin $1 \beta$ all eliminated or significantly reduced the development of incisional hernias in the rat model. (WOUND REP REG 2004;12:38-43)

Exogenous application of cytokine growth factors has been used to accelerate healing of chronic wounds. Steed et al. first reported a successful clinical trial using recombinant platelet-derived growth factor-BB (PDGF-BB) to accelerate closure of diabetic foot ulcers. ${ }^{1}$ Rees et al. used the same cytokine to shorten

From the Institute for Tissue Regeneration, Repair, and Rehabilitationa, Department of Veterans Affairs, Bay Pines, and Department of Surgery, University of South Florida, Tampa, Florida; and Department of Veterans Affairs ${ }^{\circ}$ and Department of Surgery, University of Michigan, Ann Arbor, Michigan.

Manuscript received: April 17, 2003

Accepted in final form: August 25, 2003

Reprint requests: Martin C. Robson, MD, 3619 SE Cambridge Drive, Stuart, FL 34997. Fax: (772) 2239864; Email: mcrobson@earthlink.net.

Copyright (C) 2004 by the Wound Healing Society.

ISSN: 1067-1927\$15.00+0

\begin{tabular}{|ll|}
\hline bFGF & basic Fibroblast growth factor \\
CMC & Carboxymethylcellulose \\
IGF & Insulin-like growth factor \\
IL-I $\beta$ & Interleukin-1 $\beta$ \\
KGF-2 & Keratinocyte growth factor-2 \\
MMP & Matrix metalloproteinase \\
PBS & Phosphate buffered saline solution \\
PDGF-BB & Platelet-derived growth factor-BB \\
TGF- $\beta_{2}$ & Transforming growth factor- $\beta_{2}$ \\
\hline
\end{tabular}

the time of healing of pressure ulcers. ${ }^{2}$ Robson et al. demonstrated that basic fibroblast growth factor (bFGF) could also decrease the size of pressure ulcers more effectively than a placebo control. ${ }^{3}$ Keratinocyte growth factor-2 (KGF-2) appears to have been effective in achieving closure in venous stasis ulcers, as has transforming growth factor- $\beta 2\left(\mathrm{TGF}-\beta_{2}\right){ }^{4,5}$

Clinical success in treating chronic wounds with exogenous cytokine growth factors has been 
disappointing. Despite numerous clinical trials, only one growth factor has been approved by the US Food and Drug Administration for clinical use. There are several reasons for this situation. ${ }^{6}$ Chronic wounds have a significant bacterial burden that is often not controlled prior to treatment with growth factors. Because bacteria degrade cytokine growth factors, larger amounts are required to be effective. ${ }^{7}$ In addition to the degradation of the cytokine growth factors, bacteria produce proteases including matrix metalloproteinases (MMPs), both by themselves and as a product of bacterial action on tissue cells. ${ }^{7}$ These proteases and MMPS can degrade not only the growth factor molecules but also the cytokine receptors. ${ }^{8,9}$

The acute wound, especially the surgical incision, is a closed wound with a bacterial burden 100 - to 1,000-fold less than the chronic wound. ${ }^{10}$ Cytokine growth factors have been shown to accelerate the rate of gain of tensile strength in experimental incisions. ${ }^{11-13}$ This occurs by shifting the wound healing trajectory curve to the left. ${ }^{14}$ Not only can this be done at the time of surgical incision, but as demonstrated by Smith et al., it can be accomplished by initiating the inflammatory phase of healing prior to tissue injury by injecting cytokine growth factors in the area of the intended incision. ${ }^{15}$ Combining this pretreatment with a cytokine growth factor at the time of incision nearly doubled the breaking strength of the acute wound. ${ }^{15}$

Acute wounds limited to the skin and subcutaneous tissue, although providing an experimental model, usually heal clinically without significant morbidity. Therefore, using a cytokine growth factor to more rapidly gain tensile strength has no clinical utility. However, deeper acute wounds involving the loadbearing fascia and other layers of the abdominal wall can present a major clinical problem. When acute wound failure occurs in an incision into the abdominal cavity, fascial dehiscence or an incisional hernia is the result. Pre-operative studies with long-term follow up report an 11-20 percent incidence of primary incisional hernia following laparotomy. ${ }^{16}$ With approximately 4 million abdominal operations performed annually in the United States; this rate predicts 440,000-800,000 incisional hernias in this population. ${ }^{17}$ According to the National Center for Health Statistics, approximately 200,000 operations are performed each year to repair ventral incisional hernias in the United States alone. ${ }^{17}$ It is worrisome that the frequency of this acute wound failure has not diminished appreciably in the past 75 years. ${ }^{18}$

The problem of incisional hernias is intensified by the high recurrence rate after repairs. Incisional hernia recurrence rates range from 24 to 54 percent following primary repair. ${ }^{16} \mathrm{~A}$ purely mechanical approach to acute fascial wound failure has therefore not significantly reduced the incidence of this important surgical problem. ${ }^{19}$
An incisional hernia occurs as the result of a biomechanical failure of the acute fascial wound early in the healing trajectory when wound tensile strength is very low or absent (days $0-30) .^{20}$ It is during this time when wound strength depends entirely on suture integrity that recovering patients are returning to increased levels of activity and placing increasing loads across their acute wounds. ${ }^{19}$ Cytokine growth factors are an important class of tissue repair-signaling peptides upregulated during the earliest phases of acute wound healing. ${ }^{6,21}$ However, 5-7 days are required before peak levels of fibroproliferative growth factors such as TGF- $\beta$ are reached in acute wounds. ${ }^{22}$ It was the purpose of this study to determine whether providing exogenous cytokine growth factors prior to the normal physiologic peak can biologically accelerate strengthening of a fascial wound, thus preventing acute wound failure and formation of an incisional hernia.

\section{MATERIALS AND METHODS}

Seventy-six Sprague-Dawley rats weighing 275-300g (Harlan Laboratories, Indianapolis, IN) were acclimated to laboratory conditions and fed standard rat chow and water ad libitum. All procedures were performed with the prior approval of the Ann Arbor Veterans Affairs Medical Center Institutional Animal Care and Use Committee (Ann Arbor, MI).

Animals were randomly assigned into one of ten groups. Group $1(n=16)$ underwent midline celiotomy through the linea alba and received no further treatment. In Group $2(n=8)$ the vehicle control for the aqueous cytokine growth factors was injected into the midline fascia immediately prior to incision (phosphate buffered saline solution [PBS]) and in Group 3 the vehicle for becaplermin ( 0.1 percent caboxymethylcellulose $[\mathrm{CMC}])$ was injected into the midline fascia prior to incision $(n=6)$. In Groups 4-10 $(n=46)$, the midline fascia was treated with $1 \mu \mathrm{g}$ of TGF- $\beta_{2}, 5 \mu \mathrm{g}$ of aqueous PDGF, $100 \mu \mathrm{l}$ of becaplermin (Regranex), $1 \mu \mathrm{g}$ of insulinlike growth factor (IGF), $1 \mu \mathrm{g}$ of granulocyte macrophagecolony stimulating factor (GM-CSF), or $1 \mu \mathrm{g}$ of interleukin-1 $\beta$ (IL-1 $\beta$ ) immediately prior to incision.

\section{Incisional hernia model}

Following intraperitoneal injection of ketamine $(87 \mathrm{mg} /$ $\mathrm{kg})$ and xylozene $(13 \mathrm{mg} / \mathrm{kg})$ for anesthesia, ventral abdominal hair was shaved with electric clippers and the field was prepped with alcohol solution. A 6-cm full-thickness dermal incision was placed $2 \mathrm{~cm}$ lateral to the ventral midline and a rectangular skin flap was subsequently fashioned and raised through the avascular prefascial plane, exposing the linea alba. ${ }^{19}$ A $3-\mathrm{cm}$ isolated celiotomy incision was then placed through the fascia of the midline linea alba, thereby separating 
the skin incision from the underlying fascial wound. The design of this ventral abdominal wall dermal flap model allows acute fascial healing to occur isolated from the overlying dermal wound. ${ }^{23}$ The fascial incision was then closed with a single 5-0 plain catgut suture placed across the mid-wound with $0.5 \mathrm{~cm}$ bites. Previous experience with this model predicts an 80 percent incidence of fascial incisional hernias after 28 days. ${ }^{19,24}$ The skin flap was then replaced and the dermal incisions were closed with a running 4-0 polygalactone suture. Following 30 minutes of recovery under heat lamps, the rats were returned to individual cages. Standard chow and water were again provided ad libitum.

\section{Exogenous cytokine growth factor treatment}

In Group 2, $100 \mu$ l of vehicle (PBS) was injected evenly into the linea alba using a tuberculin syringe immediately prior to fascial incision ("priming") ${ }^{15}$ In Group $3,100 \mu \mathrm{l}$ of $\mathrm{CMC}$ vehicle was injected for the priming becaplermin control. In Groups 4-10, $100 \mu \mathrm{l}$ of the test cytokine was used as the priming solution. A $3.0-\mathrm{cm}$ midline celiotomy was then performed and the fascial incision was immediately closed with a single $5-0$ plain catgut suture placed across the mid wound, as described above.

\section{Tissue processing}

All rats were killed on postoperative day 28 by intraperitoneal pentobarbitol overdose $(100 \mathrm{mg} / \mathrm{kg})$ or $\mathrm{CO}_{2}$ asphyxiation. The entire abdominal wall was then excised and the skin separated from the musculofascial layer. The peritoneal and subcutaneous surfaces of each abdominal wall were then carefully inspected for the presence of herniated abdominal contents. A minimum of $2 \mathrm{~mm}$ fascial separation was required for a wound to be scored as containing an incisional hernia. ${ }^{19,24}$ Sagittal fascial wound and/or hernia sections were then cut and immediately fixed in 10 percent buffered formalin. The fixed sections were embedded in paraffin, sectioned, and stained with hematoxylin and eosin (H\&E).

\section{Statistical analysis}

Data was analyzed using Sigma Stat software (Jandel Scientific, Corte Madera, CA). The Chi-squared test was used to determine differences in the incidence of incisional hernias. $p$-values of $<0.05$ were considered significant.

\section{RESULTS}

Incisional hernias developed in 83 percent (13/16) of the untreated fascial incisions and in 88 percent (7/8) and 83 percent (5/6) of the two vehicle control groups (Groups 2 and 3) after 28 days. (Table 1) TGF- $\beta_{2}(12$
Table 1. Incidence of ventral incisional hernia formation with or without cytokine growth factor priming of the abdominal wall prior to wound closure

\begin{tabular}{lrc}
\hline Treatment modality & N & Number of incisional hernias (\%) \\
\hline Untreated control & 16 & $13(83)$ \\
PBS control & 8 & $7(88)$ \\
CMC control & 6 & $5(83)$ \\
PDGF priming & 6 & $6(100)$ \\
Becaplermin priming & 6 & $6(100)$ \\
GM-CSF priming & 6 & $6(100)$ \\
IGF-1 priming & 6 & $6(100)$ \\
TGF- $\beta$ & 8 & $1(12) *$ \\
bFGF & 8 & $2(25)^{*}$ \\
IL-1 & 6 & $3(50) \dagger$ \\
\hline
\end{tabular}

*Significantly different compared to control $(p<0.05)$.

$\dagger$ Not significantly different compared to control $(\mathrm{p}=0.14)$.

percent, 1/8), bFGF (25 percent, 2/8) and IL-1 $\beta$ (50 percent, $3 / 6$ ) all significantly lowered the incidence of incisional hernia formation $(p<0.05)$. The remaining cytokine growth factor-treated incisions revealed no changes in the incidence of acute wound failure (aqueous PDGF-BB, becaplermin, IGF and GM-CSF [Table 1]). Accelerated fascial repair was associated with abundant collagen and extracellular matrix deposition and neovascularization (Figure 1).

There were two deaths during the study period, both due to acute herniation and or strangulation. One acute herniation occurred in each of the becaplermin and IGF groups.

\section{DISCUSSION}

Acute wound failure remains a frequent source of morbidity and mortality following injury. Abdominal wall

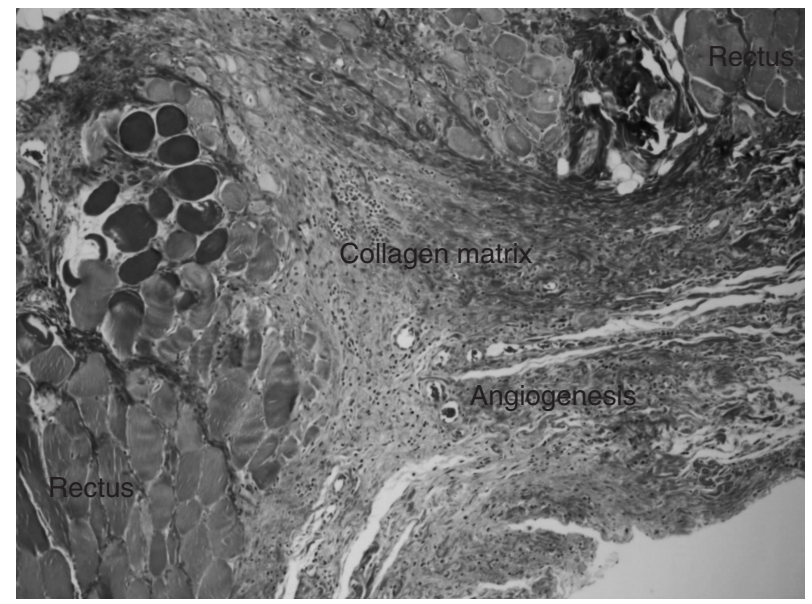

FIGURE 1. Representative histological specimen of a 28-day midline fascial incision primed with $1 \mu \mathrm{g}$ of TGF- $\beta$ that did not herniate. There is enhanced fibroplasia and abundant neovascularization. (Trichrome staining, original magnification $\times 200$ ) 
fascial dehiscence and incisional herniation are common. Prospective, well-controlled studies find that incisional hernias complicate 11 percent of all abdominal wall closures following celiotomy. ${ }^{20}$ In one of three abdominal wall closures, the fascial layer of the wound fails to heal in patients operated upon for aortic aneurysm disease, during periods of hemodynamic instability or in those with gross contamination of the deep wound space, especially in malnourished patients. ${ }^{18}$ The result is 200,000 incisional hernia repairs that are performed each year in the United States at a financial cost of nearly 2.5 billion dollars. ${ }^{17}$ With nearly four million abdominal and pelvic operations performed each year in the United States, it is estimated that another 200,000 incisional hernias may be going unrecognized or untreated.

Incisional hernias occur as the result of the combined bio-mechanical failure of an acute fascial wound early in the healing trajectory. This is not surprising when considering the clinically relevant impediments to acute tissue repair together with the normal function of the abdominal wall to support increasing loads during the postoperative recovery period. ${ }^{17,24}$ Most studies now support the concept that acute fascial separation occurs early in the postoperative period, leading to the delayed clinical development of abdominal wall incisional hernias. Mechanical failure occurs early in the trajectory of acute wound healing at a time when wound tensile strength is very low or absent (postoperative days 0 30 ). It is during the earliest period of acute wound healing that the wound depends entirely on suture integrity to maintain abdominal wall closure. Simultaneously, most patients are recovering from their procedures and returning to increased levels of activity and placing increasing loads across the acute wound during its weakest phase. The most frequently identified clinical risk factors for primary fascial wound failure and primary incisional hernia formation include a suboptimal closure technique, deep wound infections, malnutrition, peri-operative hypotension, steroid use, and aortic aneurysm disease. ${ }^{18}$

Abnormal progression of the acute wound healing trajectory impairs the recovery of wound tensile strength. ${ }^{14}$ A biological intervention at the host wound level designed to optimize fascial healing may prevent and/or treat incisional hernias. To date, systematic studies have been difficult due to the lack of a reproducible animal model of incisional hernias. A model of incisional hernia formation was therefore designed with the intentional early failure of the fascial suture. ${ }^{19}$ In this rodent model, there is progressive midline abdominal wall wound healing failure that reliably results in acute fascial separation early in the postoperative period. The incisional hernias that develop have a well-defined hernia ring, hernia sacs, and visceral adhesions, all characteristic of the incisional hernias that clinically develop in humans.
The cellular and molecular pathways of acute tissue repair are easily conceptualized as a sequence of three time-limited phases: hemostasis/inflammation (lag), proliferative, and remodeling (Figure 2). The "lag" designation attributed to the initial inflammatory phase of acute wound healing represents the time required for recruiting the many cellular elements activated during early repair and the total absence of mechanical strength that exists for several days to weeks. Fundamental among the cellular and biochemical events occurring during each of these phases of acute tissue repair are release or activation of molecular cytokine messengers that regulate cell-cell and cell-matrix interactions during wound repair. ${ }^{21}$

The improved understanding of the cellular and molecular pathways activated during acute tissue repair now allows the application of biological approaches to the problem of incisional hernia formation. This study showed that augmenting biological growth factor levels during the lag period of acute fascial repair prevents the formation of incisional hernias. Endogenous tissue growth factors are an important class of repair-signaling peptides up-regulated during the inflammatory phase of acute wound healing. Growth factors recruit and activate the cellular and molecular components necessary for the fibroproliferative burst that characterizes the lag phase of acute wound healing. Acute wound therapy with proliferative growth factors was shown to accelerate the appearance of fibroblasts and collagen into the wound, thereby shortening the natural lag-phase for gain in injured tissue tensile strength. Several reports have shown the fibroproliferative and prominent

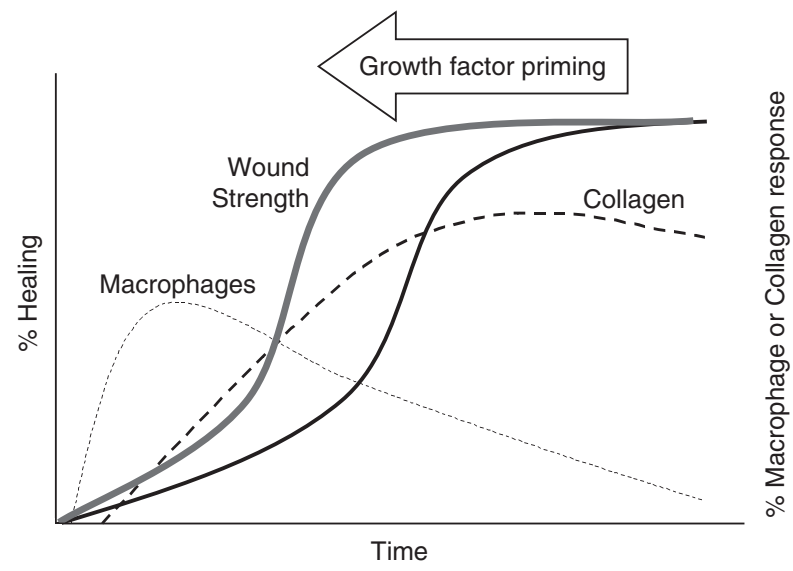

FIGURE 2. Growth factor priming of acute wound sites preactivates the cellular and molecular components of acute tissue repair prior to tissue injury. The surgical and pharmacological strategy is to shorten or eliminate the lagphase for tissue repair. This is especially important for loadbearing structures like the abdominal wall where a temporal balance must be struck between increased wound loads and the assembly of the tissue repair components required to withstand that mechanical force. 
angiogenesis-stimulating ability of bFGF in the dermis. ${ }^{25}$ The current study was designed to determine whether other cytokine growth factors more efficiently accelerate fascial incisional wound healing, thereby reducing the incidence of incisional hernia formation.

Biologically augmenting fascial repair following celiotomy lowered the incidence of fascial separation in the rat model of intentional abdominal wall wound failure. bFGF treatment induced pronounced angiogenesis, earlier fibroplasia, and enhanced collagen production within the acute fascial wound. In vivo, bFGF appears in high initial peak concentration in the early acute wound fluid (within 48 hours), and then tapers off to baseline levels within a few days. ${ }^{26}$ This pharmacokinetic pattern is characteristic of IGF, epidermal growth factor, PDGF-AB, and TGF- $\beta 1 .^{27}$ The earlyresponse growth factors are known to recruit the cellular and molecular events necessary for the transition to the fibroproliferative stage. Specifically, bFGF stimulates endothelial cell proliferation and induces the production of proteases, required for neovessel penetration through the extracellular matrix. ${ }^{27}$ Basic FGF also has modest fibroproliferative-stimulating properties. These biological functions theoretically make bFGF the ideal growth factor for penetrating the organized mature dense scar that characterizes incisional hernia rings with proteases and stimulating neovascularization to support primary apposition of the fascial edges. Several other advantageous clinical applications for bFGF have been shown in experimental animal models of acute wound healing in tissues with relatively poor blood supply. Incorporation of tracheal autografts, devascularized sternal wound healing, fractured bone healing, and tendon repair have all been shown to have enhanced wound healing with the application of bFGF to the acute wound.$^{28-30} \mathrm{bFGF}$ also improves healing parameters in patients with dysfunctional wound repair such as those with diabetes mellitus. ${ }^{31}$

Growth factor delivery remains a difficult problem in models of acute wound healing. Previously described techniques all have shortcomings. Applying the growth factors as an aqueous preparation to an open incision makes containment within the wound difficult and equal distribution throughout the wound nearly impossible. CMC suspensions improve the handling and delivery of growth factors for open wound models, but are cumbersome and unreliable for closed primary wounds. Fibrin-based carriers can also improve growth factor delivery but may act as mechanical barriers to incision healing at specific concentrations. We previously reported an aqueous TGF- $\beta 2$ preparation injected into the prospective wound site prior to incision using a small-diameter needle system. ${ }^{19}$ This "priming" of the tissue prior to injury allows ease of handling but had the shortcomings of a single-dose delivery and difficult application in the treatment of developed incisional hernias with separated fascial edges.

While predominantly fibroproliferative and angiogenic growth factors like TGF- $\beta$ and bFGF lowered the incidence of herniation, aqueous and CMC-bound PDGF may have actually impaired fascial acute fascial healing, possibly due to an abnormally prolonged or intense inflammatory phase. This may also be the reason GM-CSF had no effect or even an inhibitory effect on fascial repair. The observation that IL-1 trended toward a significant reduction in the incidence of incisional herniation was a surprise. Others have reported the property of IL-1 to stimulate apoptotic fibroblasts derived from chronic dermal wounds back into a proliferative cell cycle. ${ }^{32}$ The same effect may have been observed in this study of acute wound failure. We previously showed that acute fascial wound fibroblasts undergo cell-cycle arrest and perhaps apoptosis soon after the loss of mechanical signaling when fascial separation occurs. ${ }^{33}$

Clinically, a combined biomechanical approach similar to the one reported here may be applied especially in cases where there is a high risk for acute fascial wound failure. These would include, for example, recurrent incisional herniorrhaphy, acute wounds in patients older than 60, those closed during hemodynamic instability or in the setting of abdominal sepsis, severely malnourished patients, and those wounds associated with abdominal aortic aneurysm or morbid obesity surgery. Acute wound therapy with proliferative growth factors offers a promising new strategy for reducing the incidence of this common surgical complication.

\section{ACKNOWLEDGMENTS}

Supported in part by a VA Merit Review Grant.

\section{REFERENCES}

1. Steed D. Diabetic Ulcer Study Group. Clinical evaluation of recombinant human platelet derived growth factor (rhPDGF-BB) for the treatment of lower extremity diabetic ulcers. J Vasc Surg 1995;21:71-81.

2. Rees RS, Robson MC, Smiell SM, Perry BH. The Pressure Ulcer Study Group. Becaplermin gel in the treatment of pressure ulcers: a randomized, double-blinded, placebo-controlled study. Wound Rep Reg 1999;7:141-7.

3. Robson MC, Phillips LG, Lawrence WT, Bishop JB, Youngerman JS, Hayward PG, Broemeling LD, Heggers JP. The safety and effect of topically applied recombinant basic fibroblast growth factor on healing of chronic pressure sores. Ann Surg 1992;216:401-8.

4. Robson MC, Phillips TH, Falanga V, Odenheimer DJ, Parish LC, Jensen JL, Steed DL. Randomized trial of topically applied repifermin (recombinant human keratinocyte growth factor-s) to accelerate wound healing in venous ulcers. Wound Rep Reg 2001;9:347-52.

5. Robson MC, Phillips LG, Cooper DM, Lyle WG, Robson LE, Odom L, Hill DP, Hanham AF, Ksander GA. Safety and effect 
of transforming growth factor- $\beta_{2}$ for the treatment of venous stasis ulcers. Wound Rep Reg 1995;3:157-67.

6. Robson MC, Mustoe TA, Hunt TK. The future of recombinant growth factors in wound healing. Am J Surg 1998;176 (Suppl.):80S-82S.

7. Payne WG, Wright TE, Ko F, Wang X, Robson MC. Bacterial degradation of growth factors. J Appl Res 2003;3:35-40.

8. Yager DR, Chen SM, Ward SI, Olutoye OO, Diegelmann RF, Cohen IK. Ability of chronic wound fluids to degrade peptide growth factors is associated with increase levels of elastase activity and diminished levels of proteinase inhibitors. Wound Rep Reg 1997;5:23-32.

9. Hasan A, Murata H, Falabella A, Ochoa S, Zhou L, Badiavas E, Falanga V. Dermal fibroblasts from venous ulcers are unresponsive to the action of transforming growth factor-beta 1. J Dermatol Sci 1997;16:59-66.

10. Robson MC. Wound infection. a failure of wound healing caused by an imbalance of bacteria. Surg Clin N Am 1997;77:637-50.

11. Mustoe TA, Pierce GF, Thomason A, Gramates P, Sporn MB, Deuel TF. Accelerated healing of incisional wounds in rats induced by transforming growth factor beta. Science 1987;237:1333-6.

12. LeGrand EK. Preclinical promise of Becaplermin (rhPDGF-BB) in wound healing. Am J Surg 1998;176 (Suppl.):48S-54S.

13. Kiritsky CP, Lynch AB, Lynch SE. Role of growth factors in cutaneous wound healing: a review. Crit Rev Oral Biol Med 1993;4:729-60.

14. Franz MG, Robson MC. The use of the wound healing trajectory as an outcome determinant for acute wound healing. Wound Rep Reg 2000;8:511-6.

15. Smith PD, Kuhn MA, Franz MG, Wachtel TL, Wright TE, Robson MC. Initiating the inflammatory phase of incisional healing prior to tissue injury. J Surg Res 2000;92:11-7.

16. Luijendijk RW, Hop WCJ, Vandentol MP, deLange DCD, Braaksma MMJ, Ijezermans JNM, Boelhouwer RU, deVries BC, Salu MKM, Wereldsma JCJ, Bruijninckx CMA, Jeekel J. A comparison of suture repair with mesh repair for incisional hernia. N Engl J Med 2000;343:392-8.

17. National Center for Health Statistics. Detailed diagnoses and procedures. National Hospital Discharge Survey, Series 13, No. 122, 1995.

18. Carlson MA. Acute wound failure: wound healing. Surg Clin N Am 1997;77:607-36.

19. Franz MG, Kuhn MA, Nguyen K, Wang X, Ko F, Wright TE, Robson MC. Transforming growth factor $\mathrm{B}_{2}$ lowers the incidence of incisional hernias. J Surg Res 2001;97:109-16.
20. Santora TA, Rosylyn JJ. Incisional hernia: hernia surgery. Surg Clin N Am 1993;73:557-70.

21. Robson MC, Steed DL, Franz MG. Wound healing; biologic features and approaches to maximize healing trajectories. Curr Problems Surg 2001;38:61-140.

22. Cromack DT, Sporn MB, Roberts AB, Merino MJ, Dart LL, NortonJA. Transforming growth factor beta levels in rat wound chambers. J Surg Res 1987;42:622-8.

23. Franz MG, Smith PD, Wachtel TL, Wright TE, Kuhn MA, Ko F, Robson MC. Fascial incisions heal faster than skin. a new model of abdominal wall repair. Surgery 2001;129:203-8.

24. Franz MG, Kuhn MA, Nguyen K, Wang X, Ko F, Wright TE, Robson MC. A biologic approach to prevention and treatment of incisional hernias. Surg Forum 2000;51:585-7.

25. Montesano R, Vassalli J-D, Gaird A, Guillemin R, Orci L. Basic fibroblast growth factor induces angiogenesis in vitro. Proc Natl Acad Sci USA 1986;83:7297-301.

26. Brem H, Vogt PM, Klagsburn M, Grosfield J, Erikson E, Folkman S, Wantanabe H, Tamurahopuils G, Marikovsky. Temporal expression of basic fibroblast growth factor during wound healing. Surg Forum 1992;43:664-7.

27. Vogt PM, Lehnhardt M, Wagner D, Jansen V, Krieg M, Steinau HU. Determination of endogenous growth factors in human wound fluid: temporal presence and profiles of secretion. Plast Reconstr Surg 1998;102:117-23.

28. Nakanishi R, Hashimoto M, Yasumoto K. Improved airway healing using basic fibroblast growth factor in a canine autotransplantation model. Ann Surg 1998;227:446-54.

29. Iwakura A, Tabata Y, Nishimura K, Nakamura T, Shimizu Y, Fujita M, Komeda M. Basic fibroblast growth factor may improve devascularized sternal healing. Ann Thor Surg 2000;70:824-8.

30. Radomsky ML, Thompson AY, Spiro RC, Poser JW. Potential role of fibroblast growth factor in enhancement of fracture healing. Clin Orthop Rel Res 1998;(355 Suppl.):S283-93.

31. Greenhalgh DG, Sprugel KH, Murray MJ, Ross R. PDGF and FGF stimulate wound healing in the genetically diabetic mouse. Am J Path 1990;136:1235-46.

32. Vande Berg JS, Robson MC, Mikhail RJ. Extension of the life span of pressure ulcer fibroblasts with recombinant human interleukin-1 beta. Am J Pathol 1995;146:1273-82.

33. Franz MG, Adamson BS, Wang X, Wachtel TL, Robson MC. Accelerated acute fascial healing is associated with increased fibroblast PCNA and p21 expression. Surg Forum 2001;52: 